\title{
Developing Commercial Production of Semi-Synthetic Artemisinin, and of $\beta$-Farnesene, an Isoprenoid Produced by Fermentation of Brazilian Sugar
}

\author{
Kirsten R. Benjamin, ${ }^{a}$ Iris R. Silva ${ }^{b}$ João P. Cherubim, ${ }^{c}$ Derek McPhee ${ }^{a}$ and \\ Chris J. Paddon*,a \\ ${ }^{a}$ Amyris, Inc., 5885 Hollis Street, Suite 100, CA 94608 Emeryville, USA \\ ${ }^{b}$ Amyris Brasil Ltda, Rua John Dalton 301-Bloco B-Edificio 3, Condominio Techno Plaza, \\ 13069-330 Campinas-SP, Brazil
}

'Amyris Brasil Ltda, Rodovia Brotas/Torrinha-km 7.5, 17380-000 Brotas-SP, Brazil

\begin{abstract}
The antimalarial drug artemisinin and the specialty chemical $\beta$-farnesene are examples of natural product isoprenoids that can help solve global challenges, but whose usage has previously been limited by supply and cost impediments. This review describes the path to commercial production of these compounds utilizing fermentation of engineered yeast. Development of commercially viable yeast strains was a substantial challenge that was addressed by creation and implementation of an industrial synthetic biology pipeline. Using the engineered strains, production of $\beta$-farnesene from Brazilian sugarcane offers several environmental advantages. Among the many commercial applications of $\beta$-farnesene, its use as a feedstock for making biodegradable lubricants is highlighted. This example, along with others, highlight a powerful new suite of technologies that will become increasingly important for production of chemicals, spanning from pharmaceuticals through commodity chemicals.
\end{abstract}

Keywords: artemisinin, farnesene, fermentation, natural product, lubricant

\section{Introduction}

Brazil is endowed with great biodiversity, resulting in a huge variety of natural products. ${ }^{1-3}$ Investigation of natural products has huge value, and a subset of these chemicals from nature will have evident uses, perhaps as medicines or within the realm of functional materials. An inherent difficulty of many natural products is that they are secondary metabolites present at such low concentrations that isolation of sufficient quantities of pure material for testing, let alone commercial production, is often difficult, impossible, or environmentally destructive. This review describes the path to commercial production of two natural products, both plant isoprenoids, by Amyris, Inc., a renewable products company headquartered in California, USA, with laboratories and commercial production in São Paulo State, Brazil. ${ }^{4}$ The first product, semi-synthetic artemisinin, is an essential anti-malarial drug currently manufactured by the French pharmaceutical company Sanofi, using an engineered yeast strain developed and provided by Amyris.

*e-mail: paddon@amyris.com
At the start of production, Sanofi pursued supplementing the agricultural supply of artemisinin with semi-synthetic artemisinin. Progress in manufacturing ACTs (Artemisinin Combination Therapies, the World Health Organization recommended anti-malarial treatment) using semi-synthetic artemisinin has been recently summarized. ${ }^{5}$ After delivery of the manufacturing strain to Sanofi in 2008, the yeast strains developed for this project were further modified and improved for the production of another isoprenoid, trans$\beta$-farnesene [(6E)-7,11-dimethyl-3-methylidenedodeca1,6,10-triene; CAS RN No. 18794-84-8, hereafter referred to as simply $\beta$-farnesene], a molecule with many uses as a specialty chemical and petroleum substitute. $\beta$-Farnesene is now commercially produced by fermentation of Brazilian cane sugar in São Paulo State using engineered yeast. Development of lubricants from $\beta$-farnesene is described as an example of advances in functional materials that can be derived from the large-scale industrial production of a natural product via fermentation.

Isoprenoids are members of a large class of natural products with over 55,000 members. ${ }^{6}$ Biological synthesis of isoprenoids proceeds by the successive assembly of 
5-carbon isoprene (2-methyl-1,3-butadiene) units according to the biogenic isoprene rule. ${ }^{7}$ The common biochemical precursor of all isoprenoids is the 5-carbon intermediate isopentyl diphosphate (IPP). There are two known pathways for the biosynthesis of isoprenoids: the mevalonate pathway (MVA) ${ }^{8,9}$ and the methylerythritol phosphate (MEP) pathway. ${ }^{10}$ This review covers microbes engineered to produce isoprenoids via the MVA pathway; to date the MVA pathway has enabled production of considerably higher isoprenoid titers than the MEP pathway. ${ }^{11}$

\section{Developing Commercial Production of Semi-Synthetic Artemisinin}

The rationale for developing microbial isoprenoid production using large-scale fermentation of microbes engineered to manufacture these compounds is that the product will cost less, supply will be more reliable and plentiful, and production will be more ecologically sustainable. An example of this strategy is provided by the semi-synthetic artemisinin project. Artemisinin is a sesquiterpene lactone endoperoxide (Figure 1) with potent anti-malarial activity produced by the plant Artemisia annua. ${ }^{12}$ It is the key component of artemisinin combination therapies (ACTs), recommended in 2004 by the World Health Organization (WHO) for the first line treatment of malaria. ${ }^{13}$ Following the adoption of ACTs by the WHO, the price of plant-derived artemisinin increased dramatically and has fluctuated ever since between ca. $\$ 1,000$ per $\mathrm{kg}$ and less than $\$ 200$ per $\mathrm{kg}$, with supply shortages in some years. ${ }^{14}$ An alternative to the plant-derived production of artemisinin was desired to stabilize the supply and reduce the price of this essential drug. Total chemical synthesis is infeasible within the economics required for a medicine used broadly in the developing world. ${ }^{12}$ Thus, a plan was developed to produce artemisinin using biotechnology, specifically by fermentation using engineered microbes. ${ }^{15}$ The metabolic pathway for the production of artemisinic acid, a presumed late-stage precursor of artemisinin in A. annua, was elucidated during the $2000 \mathrm{~s}$, leading to a decision to first produce amorphadiene, ${ }^{16}$ the alkene precursor of artemisinin, then to develop the three-step oxidation of amorphadiene to artemisinic acid in yeast followed by chemical conversion to artemisinin (Figure 1). ${ }^{17}$ The path followed by the semi-synthetic artemisinin project, with particular emphasis on the development of fermentative production of late-stage precursors has been recently reviewed. ${ }^{14}$

Two recent schemes for conversion of artemisinic acid to artemisinin have been described, both based on the original synthesis by Roth and Acton. ${ }^{18}$ Amyris chemists published a non-photochemical route with a lab-scale yield of $23 \%,{ }^{17}$ though the process was not optimized. However, the industrial conversion used by Sanofi uses large-scale

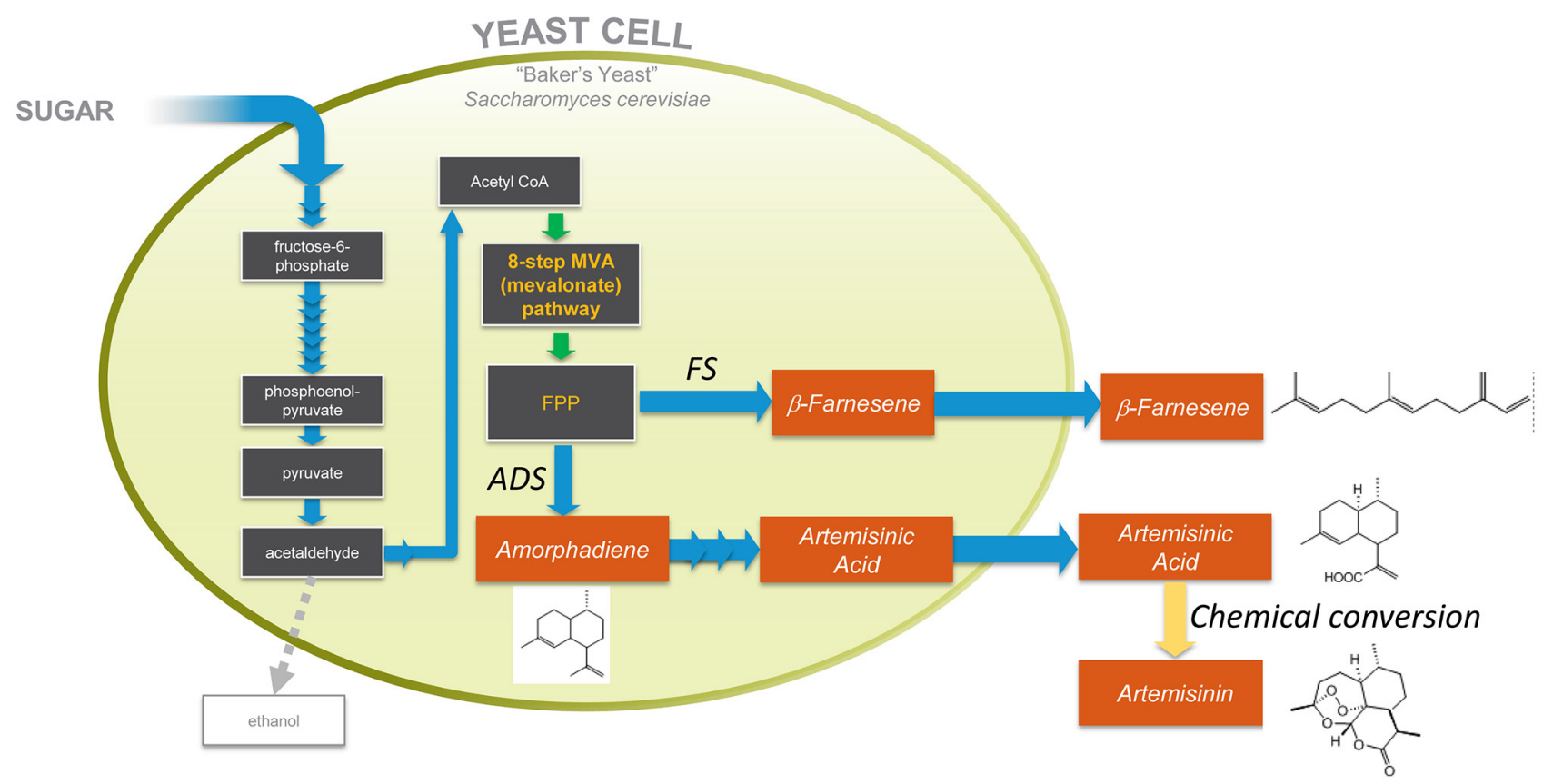

Figure 1. Production of artemisinic acid or $\beta$-farnesene by engineered yeast. The sesquiterpene alkenes $\beta$-farnesene and amorphadiene are both derived from FPP (farnesyl diphosphate) by the action of specific enzymes introduced from plants: amorphadiene synthase (ADS) generates amorphadiene and $\beta$-farnesene synthase (FS) generates $\beta$-farnesene. Production strains express either ADS or FS, not both. Oxidation of amorphadiene to artemisinic acid is accomplished by the action of five plant enzymes expressed in the engineered yeast. ${ }^{17}$ Conversion of purified artemisinic acid to artemisinin is accomplished by in vitro organic chemistry. Isoprenoid production strains make little ethanol. 
photo-Schenk ene-chemistry with specially designed and constructed large-scale photoreactors. The final optimized process delivered a $55 \%$ total yield of pure isolated artemisinin on a batch scale starting with $600 \mathrm{~kg}$ of pure fermentation-derived artemisinic acid. This process was used for production of $35 \mathrm{t}$ of semi-synthetic artemisinin in 2013 and $60 \mathrm{t}$ in $2014 .{ }^{19}$ The reaction scheme is described in Figure 2.

\section{Synthetic Biology and the Development of Commercial $\beta$-Farnesene Production Strains}

Semi-synthetic artemisinin is a pharmaceutical with a price point comparable to plant-derived artemisinin, ${ }^{20}$ namely above $\$ 150$ per $\mathrm{kg}$. $\beta$-Farnesene, however, is a specialty chemical with multiple uses (more details below); most specialty and commodity chemicals have significantly lower price points, often below $\$ 10$ per $\mathrm{kg}$. For these product categories, it is of paramount importance that fermentative production be as efficient as possible, with high yields (namely, grams of product made per gram of feed substrate), productivities (grams of product/liter of culture/hour) and concentration (also known as titer; grams of product per liter of culture). Developing yeast strains capable of the yield, productivity and titer required for chemical production requires extensive development, and has been enabled over the last decade by the new discipline of synthetic biology. Synthetic biology seeks to extend approaches and concepts from engineering and computation to redesign biology for a chosen function;21

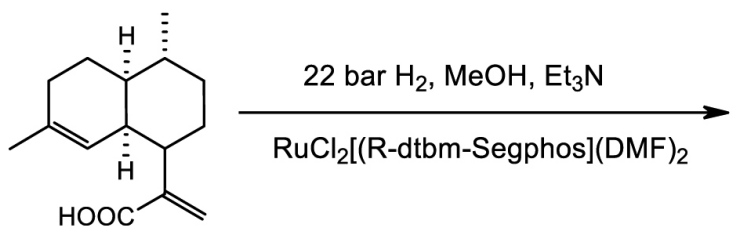

Artemisinic acid

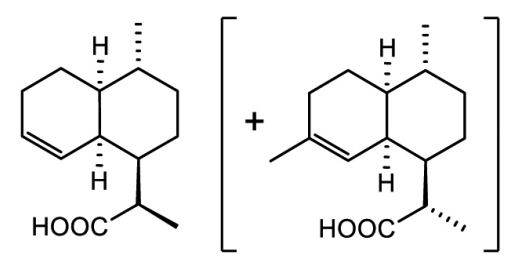

Dihydroartemisinic acid $(R)$-isomer (95): (S) isomer (5)

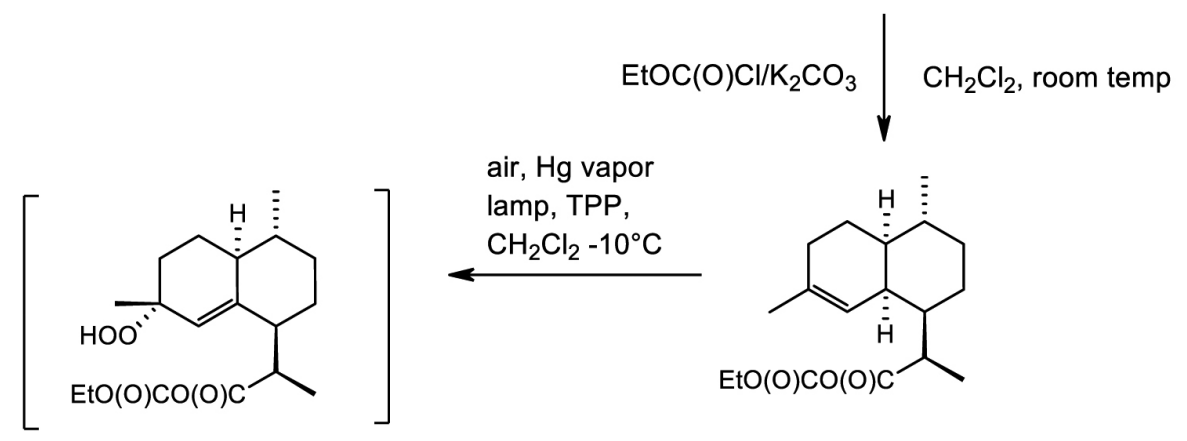

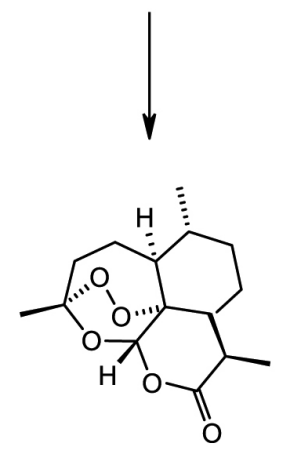

Artemisinin

Figure 2. Sanofi industrial semi-synthesis of artemisinin. The process starts with a moderate pressure catalytic diastereoselective hydrogenation of artemisinic acid to produce a high (95:5) ratio of the desired $(R)$-isomer. To avoid formation of a lactone byproduct, dihydro-epi-deoxyarteannuin B, during the photooxidation, the carboxylic acid is protected as a mixed anhydride. The final step combines formation of the intermediate hydroperoxide via photoxidation using a $\mathrm{Hg}$ vapor lamp and commercially available tetraphenylporphyin (TPP) as sensitizer with a Hock cleavage and rearrangement catalyzed by trifluoroacetic acid to give, after workup, the best yield reported to date of pure isolated artemisinin (55\%). 
recent advances in the application of design automation, i.e., the use of software, hardware and robotics ${ }^{22}$ have enabled the creation and screening of hundreds of thousands of strain variants (created by both design and random mutagenesis) for the properties required for commercial production of $\beta$-farnesene. Notable enabling technologies developed for routine usage include rapid and reliable assembly of large (i.e., multiple kilobase) deoxyribonucleic acid (DNA) constructs; ${ }^{23-25}$ high throughput, cost effective, verification of structural DNA assemblies by both initial restriction digest ${ }^{26}$ and by low-cost DNA sequencing; ${ }^{27}$ and whole genome sequencing of yeast strains. ${ }^{28}$ In addition, there is a need to effectively identify the best new strains (akin to panning for gold!) through high throughput, rapid, and accurate methods to screen thousands of strains. Further, the results of small-scale $(<1$ milliliter) tests must correspond to the results of large-scale ( $>50,000$ liter) production. Development and implementation of these technologies required considerable investment by Amyris. The outcome is a robust pipeline for efficient, cost-effective strain generation allied with screening for the properties required for commercial production of $\beta$-farnesene by fermentation (i.e., at a price point required for its use as a specialty chemical). A video compilation summarizing the uses and benefits of the above technologies is available online. ${ }^{29}$

\section{Commercial Production of $\beta$-Farnesene from Brazilian Sugar}

$\beta$-Farnesene, like amorphadiene, is a sesquiterpene aklene. The only change required from production of amorphadiene by yeast ${ }^{16}$ is to replace the plant-derived terpene synthase enzyme that catalyzes the last step, from amorphadiene synthase to $\beta$-farnesene synthase (Figure 1). This simple change was followed by multiple cycles of strain improvement using the tools of synthetic biology described above, along with fermentation and recovery process optimization, to increase the efficiency of the fermentation and thereby decrease the cost of $\beta$-farnesene production. In addition to strain performance, an important driver of the final price point of a specialty chemical such as $\beta$-farnesene is the availability and cost of sugar (i.e., the fermentation carbon source). A further consideration is life-cycle greenhouse gas (GHG) emissions for a product that will replace petroleum products as both specialty chemicals and fuels. ${ }^{30}$ The combination of cost and GHG evaluation led to the selection of Brazilian sugar cane as the preferred carbon feedstock, and construction of a $1,200 \mathrm{~m}^{3}$ fermentation plant in Brotas, SP, Brazil (Figure 3). In May 2014, Amyris was granted the highly sought-after Roundtable on Sustainable Biomaterials ${ }^{31}$ sustainability

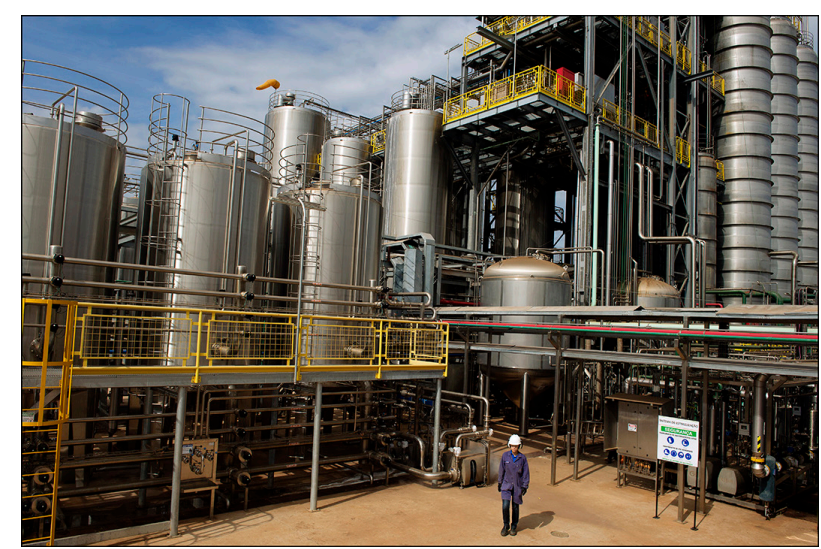

Figure 3. Amyris fermentation plant located in the city of Brotas, SP, Brazil. The 200,000 liter fermentation tanks are shown at the right of the picture.

certification for its production of $\beta$-farnesene at the Brotas plant. $^{32}$

$\beta$-Farnesene is a 15 -carbon branched-chain alkene (sesquiterpene) with a conjugated double-bond pair at its terminus, which facilitates a large diversity of chemical modifications. The isomers of farnesene are naturally produced as an alarm pheromone emitted by aphids, ${ }^{33,34}$ as a natural coating on apples ( $\alpha$-farnesene), ${ }^{35}$ and as a major component of essential oils. ${ }^{36}$ Prior to its production by fermentation it was commercially available only as an expensive chemical derived from isoprene ${ }^{37}$ or the degradation of sesquiterpene alcohols ${ }^{38}$ both of these preparation methods produced low-purity mixtures of isomers ( $\beta$-farnesene and $\alpha$-farnesene) and other byproducts. By virtue of its biological production route from engineered yeast, $\beta$-farnesene is produced as a pure enantiomer, dictated by the final enzyme in the metabolic production pathway, $\beta$-farnesene synthase.

\section{5. $\beta$-Farnesene Use as a Specialty Feedstock Chemical}

$\beta$-Farnesene has many uses as a specialty feedstock for chemical transformations that can produce a wide variety of consumer and industrial products, amongst which are cosmetic oils (e.g., squalane), ${ }^{39}$ polymers, ${ }^{40,41}$ lubricants, ${ }^{42}$ surfactants, ${ }^{41}$ and fuels. ${ }^{41}$ These large and growing markets pose significant opportunities in Brazil and abroad to utilize $\beta$-farnesene to replace petroleum-derived ingredients in numerous products that consumers use worldwide.

The technology for production of $\beta$-farnesene and its fully hydrogenated derivative, farnesane (2,6,10-trimethyldodecane), for use as a renewable hydrocarbon for diesel and jet fuel ${ }^{43}$ by Amyris was recognized with a United States Environmental Protection Agency (EPA) Presidential Green Chemistry Challenge Award in 2014. ${ }^{44}$ 
Blends of farnesane with petroleum diesel meet or exceed the existing ASTM D975-11 Standard Specifications for Diesel Fuel Oils. In Brazil, Amyris renewable diesel has been accepted for commercial use by the ANP authority (Brazilian National Agency for Petroleum, Natural Gas and Biofuels) under Resolution No. 19. Among its many advantages as a diesel fuel farnesane provides at least an $80 \%$ reduction of greenhouse gas emissions relative to petroleum-based diesel (based on California Air Resources Board metrics), zero sulfur content to meet today's stricter emissions requirements, and a demonstrated reduction of tailpipe emissions such as $\mathrm{NO}_{\mathrm{x}}$, particulate matter, and carbon monoxide, when blended with ultra-low sulfur diesel (ULSD). ${ }^{41}$ It has been tested by several OEMs (engine and vehicle manufacturers) and received OEM engine warranties from the Cummins Engine Company and Mercedes Benz Truck and Bus Company (Brazil).

In the area of fuels, which is one of the largest commodity markets in the world, longer term when more attractive economics prevail, the advantageous global impact of a biofuels solution is evident in supporting a healthier planet. However, in the interim, there are a number of attractive, focused markets that are being pursued for $\beta$-farnesene. An example of one such market, lubricants, is given below.

\section{6. $\beta$-Farnesene-Derived Lubricants}

The use of $\beta$-farnesene as a lubricant feedstock is of particular interest, given the need for environmentally friendly lubricants that can be used as drop-in substitutes for petroleum-derived products. ${ }^{42} \beta$-Farnesene is a unique biologically-derived lubricant feedstock as it is a pure hydrocarbon olefin. The lubricants industry is based on petroleum-derived hydrocarbons; $\beta$-farnesene can be used in many olefin processes already developed in the lubricants industry and can be treated similarly to linear alpha olefins (LAOs) in the production of polyalphaolefins (PAOs). Thus, production of $\beta$-farnesene-derived base oils (FDBOs) does not require the development of new process technology and infrastructure, which is a significant advantage in the path to commercialization. ${ }^{42}$ FDBOs are made chemically by reacting petroleum-based LAOs with $\beta$-farnesene to create a $50 \%$ renewable base oil. ${ }^{42}$ Being hydrocarbons, FDBOs are drop-in products in terms of usage, for example handling, compatibility, seals, specifications, disposal and rerefining when compared to petroleum products. $\beta$-Farnesene and isoprene have similar chemical structures and many of the routes to highermolecular weight isoprene polymers can be applied to $\beta$-farnesene. A variety of $\beta$-farnesene polymer processes and compositions have been developed ${ }^{42,45,46}$ The American Petroleum institute (API) classifies lubricant base oils into five groups (I-V) based on the proportion of saturates, sulfur content, and viscosity index: ${ }^{47}$ FDBOs possess the physical characteristics of Group III base oils. ${ }^{42}$ Other than the renewability credentials conferred by production from sugar, an important property of FDBOs are their ecological and biodegradability properties. FDBOs meet the requirements of the European Union (EU) Ecolabel ${ }^{48}$ which is the most stringent regulatory system developed for industrial lubricants, and are readily biodegradable when tested using the OECD 301B method, demonstrating far greater degradation than PAOs. ${ }^{42,49}$ Additionally, FDBOs exhibit low toxicity and are classified as white oils by the National Sanitation Foundation (NSF), suitable for incidental food contact. ${ }^{50}$ Extensive ecotoxicity testing has shown FDBOs to be nontoxic in key environmental areas. ${ }^{42}$ With the environmental and performance properties described above, FDBOs have been developed for an extensive range of applications. Lubricants are formulated for specific applications by the addition of performance additives to base oils; FDBOs, being hydrocarbon-based, can use off-the-shelf additive technology developed for petroleum oils, endowing the same properties that they confer on synthetic or mineral base oils. FDBOs have been formulated into high-performance hydraulic fluids, transformer oils, compressor oils, industrial gear oils, greases, automotive engine oils, and two-cycle air and marine engine oils. ${ }^{42,51}$ In summary, FDBOs have allowed the development of environmentally friendly lubricants with the performance properties of petroleum-sourced oils.

\section{Conclusion and Outlook}

As the world's population and economies grow, the demand for a wide variety of specialty, commodity, and pharmaceutical chemicals will outpace the supply available from current sources. There is an urgent need to develop alternative, sustainable sources of many existing chemicals and to develop abundant sources of currently scarce chemicals with novel beneficial properties. Synthetic biology and industrial fermentation, combined with synthetic chemistry, will be an increasingly important source of chemicals in the decades ahead; artemisinin and $\beta$-farnesene provide good examples of this relatively new approach to chemical production. Brazil's plentiful sugar cane feedstock and fermentation expertise make it an excellent location for this type of manufacturing, which can expand and diversify the nation's industrial base and international importance. 


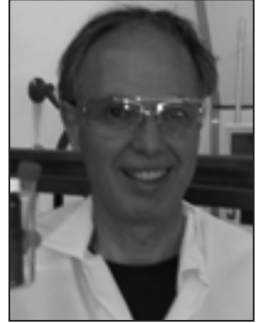

Chris Paddon is a Principal Scientist at Amyris, Inc. in Emeryville, $C A$. He was project leader for the Semi-Synthetic Artemisinin project, and subsequently led a number of projects at Amyris using synthetic biology for the production of natural products. He received his Bachelor's degree in Microbiology from The University of Surrey $(U K)$, and doctorate in Biochemistry from Imperial College (London, UK). Following postdoctoral work at The National Institutes for Health (Bethesda, MD) he joined the pharmaceutical industry, working for GSK (London, UK). He subsequently worked for Affymax (Palo Alto, CA) and Xenoport (Santa Clara, CA) before joining Amyris.

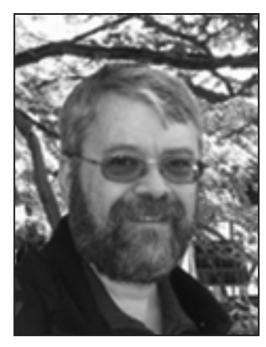

Derek McPhee is the Senior Director of Technology Strategy at Amyris Inc., where he was previously the Director/Sr. Director of Chemistry. He has a LicC in Applied Chemistry from the Universidad de Málaga (Spain) and a PhD in Organic Chemistry from the University of Calgary (Canada). After a NSERC post-doctoral fellowship at the Canadian NRC, the remainder of his career has been in industry, first in the crop protection, specialty and rubber chemicals divisions of Uniroyal Chemical (now Chemtura Corp.), then the generic pharmaceutical industry at Brantford Chemicals (now Apotex Pharmachem), and as Director of Chemistry/VP of AstaTech Canada.

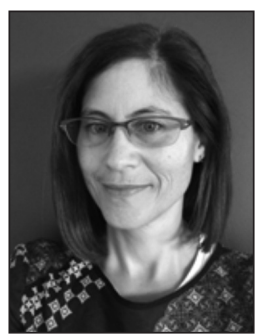

Kirsten Benjamin is a Senior Research Fellow at Amyris, Inc. in Emeryville, CA. She built and tested improved microbial strains for the Semi-Synthetic Artemisinin project and was director of the Farnesene (Biofene ${ }^{\mathrm{TM}}$ ) Strain Improvement project. She received her Bachelor's degree in Molecular and Cell Biology from the University of Michigan (USA), and her doctorate in Biochemistry from the University of California at Berkeley (USA). Following postdoctoral work at the University of California at San Francisco, she performed systems biology research at the Molecular Sciences Institute (Berkeley, CA, USA) before joining Amyris.

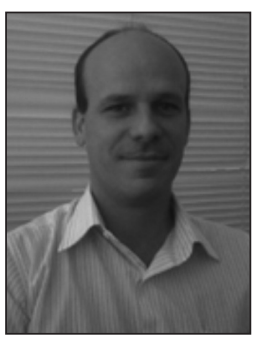

João Paulo Cherubim is Manufacturing and Process Development Director at Amyris Brazil. He has a BSc degree in Chemical Engineering and Master in Brewery Process, Sugar and Ethanol Production and in Business Managment. In the last 22 years, he was responsible for manufacturing activities at ABInbev, Imerys, Zilor and Amyris, with more than 15 years of fermentation processes expertise.

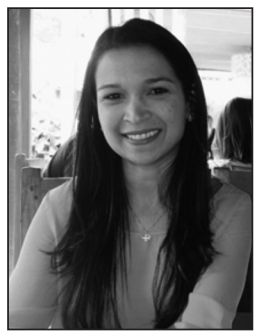

Iris R. Silva is Process Development Manager of Brazil at Amyris Brazil. She received her BSC degree in Chemical Engineering from University of São Carlos (Brazil) and has an MBA in Project Management and Business. She has worked at Amyris with fermentation and downstream processing for the last 8 years, having previously worked in production processes and currently in process development areas.

\section{References}

1. Berlinck, R. G. S.; Hajdu, E.; da Rocha, R. M.; de Oliveira, J. H. H. L.; Hernández, I. L. C.; Seleghim, M. H. R.; Granato, A. C.; de Almeida, É. V. R.; Nuñez, C. V.; Muricy, G.; Peixinho, S.; Pessoa, C.; Moraes, M. O.; Cavalcanti, B. C.; Nascimento, G. G. F.; Thiemann, O.; Silva, M.; Souza, A. O.; Silva, C. L.; Minarini, P. R. R.; J. Nat. Prod. 2004, 67, 510.

2. Valli, M.; dos Santos, R. N.; Figueira, L. D.; Nakajima, C. H.; Castro-Gamboa, I.; Andricopulo, A. D.; Bolzani, V. S.; J. Nat. Prod. 2013, 76, 439.

3. Ioca, L. P.; Allard, P.-M.; Berlinck, R. G. S.; Nat. Prod. Rep. 2014, 31, 646.

4. Amyris, Inc., available at www.amyris.com accessed in April 2016.

5. Peplow, M.; Nature 2016, 530, 389.

6. Ajikumar, P. K.; Tyo, K.; Carlsen, S.; Mucha, O.; Phon, T. H.; Stephanopoulos, G.; Mol. Pharm. 2008, 5, 167.

7. Ruzicka, L.; Experientia 1953, 9, 357.

8. Bloch, K.; Steroids 1992, 57, 378.

9. Chen, M.; Poulter, C. D.; Biochemistry 2010, 49, 207.

10. Eisenreich, W.; Bacher, A.; Arigoni, D.; Rohdich, F.; Cell. Mol. Life Sci. 2004, 61, 1401.

11. Leavell, M. D.; McPhee, D. J.; Paddon, C. J.; Curr. Opin. Biotechnol. 2016, 37, 114.

12. White, N. J.; Science 2008, 320, 330. 
13. Dalrymple, D.; 2012. http://www.mmv.org/newsroom/ publications/artemisia-annua-artemisinin-acts-malaria-controlafrica accessed in April 2016.

14. Paddon, C. J.; Keasling, J. D.; Nat. Rev. Microbiol. 2014, 12, 355.

15. Hale, V.; Keasling, J. D.; Renninger, N.; Diagana, T. T.; Am. J. Trop. Med. Hyg. 2007, 77, 198.

16. Westfall, P. J.; Pitera, D. J.; Lenihan, J. R.; Eng, D.; Woolard, F. X.; Regentin, R.; Horning, T.; Tsuruta, H.; Melis, D. J.; Owens, A.; Fickes, S.; Diola, D.; Benjamin, K. R.; Keasling, J. D.; Leavell, M. D.; McPhee, D. J.; Renninger, N. S.; Newman, J. D.; Paddon, C. J.; Proc. Natl. Acad. Sci. USA 2012, 109, E111.

17. Paddon, C. J.; Westfall, P. J.; Pitera, D. J.; Benjamin, K.; Fisher, K.; McPhee, D.; Leavell, M. D.; Tai, A.; Main, A.; Eng, D.; Polichuk, D. R.; Teoh, K. H.; Reed, D. W.; Treynor, T.; Lenihan, J.; Jiang, H.; Fleck, M.; Bajad, S.; Dang, G.; Dengrove, D.; Diola, D.; Dorin, G.; Ellens, K. W.; Fickes, S.; Galazzo, J.; Gaucher, S. P.; Geistlinger, T.; Henry, R.; Hepp, M.; Horning, T.; Iqbal, T.; Kizer, L.; Lieu, B.; Melis, D.; Moss, N.; Regentin, R.; Secrest, S.; Tsuruta, H.; Vazquez, R.; Westblade, L. F.; Xu, L.; Yu, M.; Zhang, Y.; Zhao, L.; Lievense, J.; Covello, P. S.; Keasling, J. D.; Reiling, K. K.; Renninger, N. S.; Newman, J. D.; Nature 2013, 496, 528.

18. Roth, R. J.; Acton, N.; J. Nat. Prod. 1989, 52, 1183.

19. Turconi, J.; Griolet, F.; Guevel, R.; Oddon, G.; Villa, R.; Geatti, A.; Hvala, M.; Rossen, K.; Göller, R.; Burgard, A.; Org. Process Res. Dev. 2014, 18, 417.

20. Assured Artemisinin Supply System, Artemisinin Imports into India, available at http://www.a2s2.org/market-data/ artemisinin-imports-into-india.html accessed in April 2016.

21. Way, J. C.; Collins, J. J.; Keasling, J. D.; Silver, P. A.; Cell 2014, 157, 151.

22. Densmore, D. M.; Bhatia, S.; Trends Biotechnol. 2014, 32, 111.

23. Oldenburg, K. R.; Vo, K. T.; Michaelis, S.; Paddon, C.; Nucleic Acids Res. 1997, 25, 451.

24. Kuijpers, N.; Solis-Escalante, D.; Bosman, L.; van den Broek, M.; Pronk, J.; Daran, J.-M.; Daran-Lapujade, P.; Microb. Cell Fact. 2013, 12, 47.

25. de Kok, S.; Stanton, L. H.; Slaby, T.; Durot, M.; Holmes, V. F.; Patel, K. G.; Platt, D.; Shapland, E. B.; Serber, Z.; Dean, J.; Newman, J. D.; Chandran, S. S.; ACS Synth. Biol. 2014, 3, 97.

26. Dharmadi, Y.; Patel, K.; Shapland, E.; Hollis, D.; Slaby, T.; Klinkner, N.; Dean, J.; Chandran, S. S.; Nucleic Acids Res. 2014, 42, e22.

27. Shapland, E. B.; Holmes, V.; Reeves, C. D.; Sorokin, E.; Durot, M.; Platt, D.; Allen, C.; Dean, J.; Serber, Z.; Newman, J.; Chandran, S; ACS Synth. Biol. 2015, 4, 860.

28. Nijkamp, J. F.; van den Broek, M.; Datema, E.; de Kok, S.; Bosman, L.; Luttik, M. A.; Daran-Lapujade, P.; Vongsangnak, W.; Nielsen, J.; Heijne, W. H.; Klaassen, P.; Paddon, C. J.; Platt, D.; Kotter, P.; van Ham, R. C.; Reinders, M. J.; Pronk, J. T.; de Ridder, D.; Daran, J. M.; Microb. Cell Fact. 2012, 11, 36.
29. DARPA, Amyris Living Foundries video, available at https:// amyris.com/collaborations/darpa/ accessed in April 2016.

30. Moreira, M.; Gurgel, A. C.; Seabra, J. E. A.; Environ. Sci. Technol. 2014, 48, 14756.

31. Round Table on Sustainable Biomaterials, http://rsb.org/ accessed in April 2016.

32. Amyris RSB certification http://www.rsb.org/pdfs/Press $\% 20$ Releases/May\%202014\%20-\%20RSB\%20Amyris\%20 Press\%20Release.pdf accessed in April 2016.

33. Pickett, J. A.; Griffiths, D. C.; J. Chem. Ecol. 1980, 6, 349.

34. Vandermoten, S.; Mescher, M. C.; Francis, F.; Haubruge, E.; Verheggen, F. J.; Insect Biochem. Mol. Biol. 2012, 42, 155.

35. Huelin, F. E.; Murray, K. E.; Nature 1966, 210, 1260.

36. Satyal, P.; Shrestha, S.; Setzer, W. N.; Nat. Prod. Commun. 2015, 10, 1453.

37. Kumobayashi, H.; Takayama, K.; Someya, T.; Otsuka, S.; Bull. Chem. Soc. Jpn. 1978, 51, 1158.

38. Tanaka, S.; Yasuda, A.; Yamamoto, H.; Nozaki, H.; J. Am. Chem. Soc. 1975, 97, 3252.

39. McPhee, D. J.; Pin, A.; Kizer, L.; Perelman, L.; Cosmet. Toiletries 2014, 129, 20.

40. Schofer, S. J.; McPhee, D. J.; Moriguchi, N.; Yamana, Y.; Chapman, B.; Hirata, K.; Uehara, Y.; Rubber World 2014, 4, 25.

41. McPhee, D. J. In Catalytic Process Development for Renewable Materials; Imhof, P.; van der Waal, J.-K., eds.; Wiley: Weinheim 2013, pp. 51.

42. Brown, J.; Hahn, H.; Vettel, P.; Wells, J. In Environmentally Friendly and Biobased Lubricants; Sharma, B. K.; Biresaw, G., eds.; CRC Press: Boca Raton, in press.

43. ASTM D975: Standard Specification for Diesel Fuel Oils, Philadelphia, 2013.

44. EPA, 2014, http://www.epa.gov/greenchemistry/2014-smallbusiness-award, accessed in April 2016.

45. McPhee, D. J.; US pat. 8,217,128 2012.

46. McPhee, D. J.; Safir, A.; Reeder, C. L.; Doolan, J. G.; US pat. 8,592,543 2013.

47. API, 2015, http://www.api.org/ /media/Files/Certification/ Engine-Oil-Diesel/Publications/AnnE-REV-03-25-15. pdf?la=en accessed in April 2016.

48. EU Ecolabel, http://ec.europa.eu/environment/ecolabel/ accessed in April 2016.

49. OECD 301, http://www.oecd.org/chemicalsafety/riskassessment/1948209.pdf accessed in April 2016.

50. NSF International, http://info.nsf.org/USDA/psnclistings.asp accessed in April 2016.

51. Novvi LLC, www.novvi.com accessed in April 2016.

Submitted: February 8, 2016

Published online: April 15, 2016

FAPESP has sponsored the publication of this article. 